\title{
AMBIENTES DIGITAIS VIRTUAIS: ACESSIBILIDADE AOS DEFICIENTES VISUAIS
}

\author{
Andréa Poletto Sonza ${ }^{1}$ \\ Lucila Maria Costi Santarosa $^{2}$
}

\begin{abstract}
Resumo: O objetivo deste trabalho é fornecer noções básicas sobre os principais sistemas de acessibilidade de deficientes visuais (dv's) aos ambientes digitais virtuais atualmente utilizados em nosso país, suas principais características e modo de funcionamento. Procuramos apresentar uma compilação destas "próteses" as quais objetivam o acesso de dv's aos contextos educacional e social em uma abordagem mais inclusiva.
\end{abstract}

Palavras- chave: deficiência visual, ambientes digitais, acessibilidade, inclusão

VIRTUAL DIGITAL AMBIENTS: ACCESSIBILITY TO DISABLED VISUAL

Abstract: This paper presents basic concepts about the main systems of acessibility to visual disabled (vd) to digital ambients today used in our country, your main characteristics and operation manners. We try to present one overview of this softwares that object the access to vd to the educational and social contexts in one approach more included.

Key words: visual disabled, digital ambients, accessibility, inclusion

1 Informata, Especialista em Psicopedagogia (UNISUL - SC), Mestranda em Educação (UFRGS), Professora da Rede Federal de Ensino - CEFET - Bento Gonçalves. (anjjo@ terra.com.br)

${ }^{2}$ Professora Dra. do Curso de Pós-graduação em Informática na Educação (PGIE) e do Programa de Pósgraduação em Educação (PPGEDU) da UFRGS; pesquisadora IA do CNPq e consultora da SEESP/MEC; Presidente da Redespecial-Brasil; coordenadora nacional da RIBIE (lucila.santarosa@ufrgs.br) 


\section{Introdução}

De acordo com uma pesquisa realizada pelo IBGE (Instituto Brasileiro de Geografia e Estatística) em 1991, haviam 1.668.654 pessoas com necessidades educacionais especiais - PNEEs $(1,15 \%$ da população) e segundo levantamento estatístico do MEC em 1997 somente 334.507 (2\%) recebiam algum tipo de atendimento. No que tange a deficiência visual, A Organização Mundial de Saúde (OMS) estima que nos países em desenvolvimento, como no Brasil, 1 a 1,5\% da população apresenta esta necessidade. "Assim, no Brasil haveria cerca de 1,6 milhão de pessoas com algum tipo de deficiência visual, sendo a maioria delas com baixa visão" (Gil, 2000). De acordo com dados do Senso Escolar MEC/INEP 2000, no período de 1996 a 2000, a matrícula de alunos com deficiência visual na educação básica apresentou um aumento na ordem de 134,2\%. (Santos, 2001, p.20). Por meio destes dados podemos, mesmo que prematuramente, concluir que há uma certa preocupação com as PNEEs, mas ainda falta muito para que tenhamos uma sociedade alicerçada nos ideais da inclusão.

"A construção de uma sociedade de plena participação e igualdade tem como um de seus princípios a interação efetiva de todos os cidadãos. Nesta perspectiva é fundamental a construção de políticas de inclusão para o reconhecimento da diferença e para desencadear uma revolução conceitual que conceba uma sociedade em que todos devem participar, com direito de igualdade e de acordo com suas especificidades". (Conforto \& Santarosa, 2002).

$O$ respeito a idiossincrasia de cada sujeito constitui-se em um ponto chave para o que atualmente denominamos de inclusão. E a informática tem sido uma grande aliada desses "diferentes" atravessando barreiras e quebrando obstáculos. Podemos comprovar esta afirmação através de várias pesquisas já realizadas. (Santarosa, 2002). De acordo com a autora os resultados das pesquisas demonstram que as Tecnologias da Informação e Comunicação abrem novas janelas às PNEEs amenizando assim a discriminação social comprovando que elas também são capazes e que apesar de apresentarem uma necessidade possuem um grande potencial.

Valente complementa as afirmações acima ao mencionar que as oportunidades oferecidas pelo potencial tecnológico começam a romper com a lógica racionalista excludente predominante por este constituir-se em uma valiosa ferramenta no processo de aprendizagem, busca e processamento de informações, no sentido de "propiciar aos sujeitos a oportunidade de desenvolverem atividades interessantes, desafiantes e que tenham propósitos educacionais e de diagnóstico. Estas atividades podem oferecer a eles a chance de adquirir conhecimento e sobrepujar suas deficiências intelectuais." (1991, p.1).

De acordo com Santarosa as ferramentas computacionais abrem um espaço de oportunidades, "principalmente para as pessoas cujos padrões de aprendizagem não seguem os quadros típicos de desenvolvimento. Os estudos mostram que pessoas limitadas por deficiências não são menos desenvolvidas, mas se desenvolvem de forma diferente" (2000).

A autora aponta para duas formas de uso da tecnologia: como próteses físicas e mentais. "As próteses físicas incluem o conjunto de dispositivos e procedimentos que têm por objetivo o desempenho de funções que o corpo não pode ou tem dificuldades de executar devido a deficiência" (Santarosa, 2000); já as próteses mentais objetivam o desenvolvimento cognitivo, sócio-afetivo e de comunicação. "Em muitos procedimentos 
é difícil estabelecer limites ou fronteiras para categorizar como prótese física ou mental, uma vez que elas atuam em ambas as áreas" (ibidem).

Assim, conforme a necessidade especial apresentada, e utilizando os recursos tecnológicos que a Informática nos propicia, uma "prótese" é adaptada, fazendo com que estes sujeitos se apropriem do conhecimento com maiores facilidades.

Estas próteses, também denominadas de ajudas técnicas ou auto-ajudas "referem-se ao conjunto de recursos que, de alguma maneira, contribuem para proporcionar às PNEEs maior independência, qualidade de vida e inclusão na vida social através do suplemento, manutenção ou devolução de suas capacidades funcionais". (Hogetop \& Santarosa, 2002). Podemos dizer então que através da Tecnologia Adaptativa/Assistiva Informática as mais diversas incapacidades podem ser compensadas.

No que tange a deficiência visual, a importância dos Ambientes Digitais é inquestionável. De acordo com Campbell "desde a invenção do Código Braille em 1829, nada teve tanto impacto nos programas de educação, reabilitação e emprego quanto o recente desenvolvimento da Informática para os cegos" (2001, p.107).

Conforme Borges (1996) "uma pessoa cega pode ter algumas limitações, as quais poderão trazer obstáculos ao seu aproveitamento produtivo na sociedade". Ele aponta que grande parte destas limitações pode ser eliminada através de duas ações: uma educação adaptada a realidade destes sujeitos e o uso da tecnologia para diminuir as barreiras.

Pretendemos através deste trabalho divulgar os principais sistemas de acessibilidade de deficientes visuais aos ambientes digitais utilizados atualmente em nosso país, suas principais características e modo de funcionamento. Procuramos apresentar uma compilação destas "próteses" que objetivam o acesso de dv' s aos contextos educacional e social em um panorama inclusivista.

\section{2.. Softwares de Acessibilidade aos Deficientes Visuais}

Os softwares de acessibilidade aos ambientes digitais para deficientes visuais utilizam basicamente ampliadores de tela para aqueles que possuem perda parcial da visão e recursos de áudio, teclado e impressora em Braille para os sujeitos cegos.

Dentre os sistemas para deficientes visuais ${ }^{3}$ os mais utilizados atualmente em nosso país são o Dosvox, o Virtual Vision e o Jaws.

\section{Dosvox}

É um sistema operacional para microcomputadores da linha PC (Personal Computer, - Computador Pessoal) que se comunica com o usuário através de síntese de $\mathrm{voz}^{4}$ viabilizando deste modo, o uso de computadores por deficientes visuais. O sistema "conversa" com o dv em Português.

O DOSVOX vem sendo desenvolvido desde 1993 pelo NCE - Núcleo de

\footnotetext{
${ }^{3}$ Entenda-se por deficientes visuais os sujeitos com perda visual total (cegos) e os com baixa visão.

4 Reprodução de fonemas que são gerados sem o auxílio da pré-gravação. Significa transformar informação binária (originária do computador) em sinais audíveis. Uma de suas utilidades é transformar entrada de texto em palavras audíveis para os deficientes visuais.
} 
Computação Eletrônica da UFRJ (Universidade Federal do Rio de Janeiro) sob a coordenação do professor José Antônio dos Santos Borges. A idéia de desenvolver tal programa evoluiu a partir do trabalho de um aluno com deficiência visual, Marcelo Pimentel, que hoje é programador do NCE, onde trabalha sob a orientação do Professor José Antônio Borges.

Uma das importantes características desse sistema é que ele foi desenvolvido com tecnologia totalmente nacional, sendo o primeiro sistema comercial a sintetizar vocalmente textos genéricos na língua portuguesa. Tanto o software quanto o hardware são projetos originais, de baixa complexidade, e adequados a nossa realidade.

Há duas versões do programa: uma simplificada, que pode ser capturada da Internet (gratuitamente) e outra profissional, que pode ser adquirida comercialmente, por baixo custo.

Atualmente o projeto conta com mais de 5.000 usuários espalhados pelo Brasil sendo composto por mais de 70 programas.

Como o sistema lê e digitaliza o som em português, o diálogo homem/máquina é feito de forma simples e sem "jargões". Esse programa também utiliza padrões internacionais de Computação podendo assim ser lido e ler dados e textos gerados por programas e sistemas de uso comum em Informática. Trata-se de um software simples para usuários iniciantes, de fácil instalação e utilização.

O DOSVOX apresenta o mérito de ter sido pioneiro nesta área disponibilizando um sistema completo para deficientes visuais, incluindo desde edição de textos até navegação na Internet e utilitários, o que possibilita a seus usuários uma grande variedade de opções.

Dentre as limitações do DOSVOX podemos destacar o acesso à Internet, que apresenta algumas restrições pelo fato da maioria das páginas apresentarem figuras, gráficos e frames, o que torna difícil para o deficiente visual compreender o que está sendo exibido na tela. Mas, como o sistema vem sendo aperfeiçoado a cada nova versão, ao que tudo indica este problema poderá ser minimizado.

Da equipe de desenvolvimento participam também programadores deficientes visuais, que dele fazem uso. Além disso, alunos do curso de Informática da UFRJ têm criado uma série de programas complementares.

Hoje o projeto DOSVOX é distribuído em duas versões: para $\operatorname{DOS}^{5}$ e para Windows (também chamado de WINVOX). O programa é composto por:

- Sistema operacional que contém os elementos de interface com o usuário;

- Sistema de síntese de voz para a língua portuguesa;

- Editor, leitor e impressor/formatador de textos;

- Impressor/formatador para braille;

- Diversos programas de uso geral para deficientes visuais; como caderno de telefones, agenda de compromissos, calculadora, preenchedor de cheques, cronômetro, etc.

- Jogos de caráter lúdico;

- Ampliador de telas para pessoas com visão reduzida;

- Programas para ajuda à educação de crianças com deficiência visual;

- Programas sonoros para acesso à Internet, correio eletrônico e bate-papo;

- Leitor de telas/janelas para DOS e Windows.

\footnotetext{
${ }^{5}$ MS-DOS (Microsoft - Disk Operation System) Sistema Operacional de disco da (empresa) Microsoft.
} 


\section{Funcionamento do DOSVOX}

Após instalarmos o programa DosVox no ambiente Windows, um ícone do mesmo aparecerá na tela. Acessando esta janela, (através do ícone ou das teclas "CTRL+ALT+D") uma outra abrir-se-á com a tela de abertura do DosVox (figura 1). A primeira pergunta feita pelo sistema é: "Dosvox - o que você deseja?" Caso o usuário não saiba como escolher a opção, deve simplesmente digitar a tecla "F1" (ajuda). Desse modo as opções aparecerão na tela sendo digitalizadas pelo programa, cabendo ao usuário digitar a letra correspondente à opção desejada (figura 2).

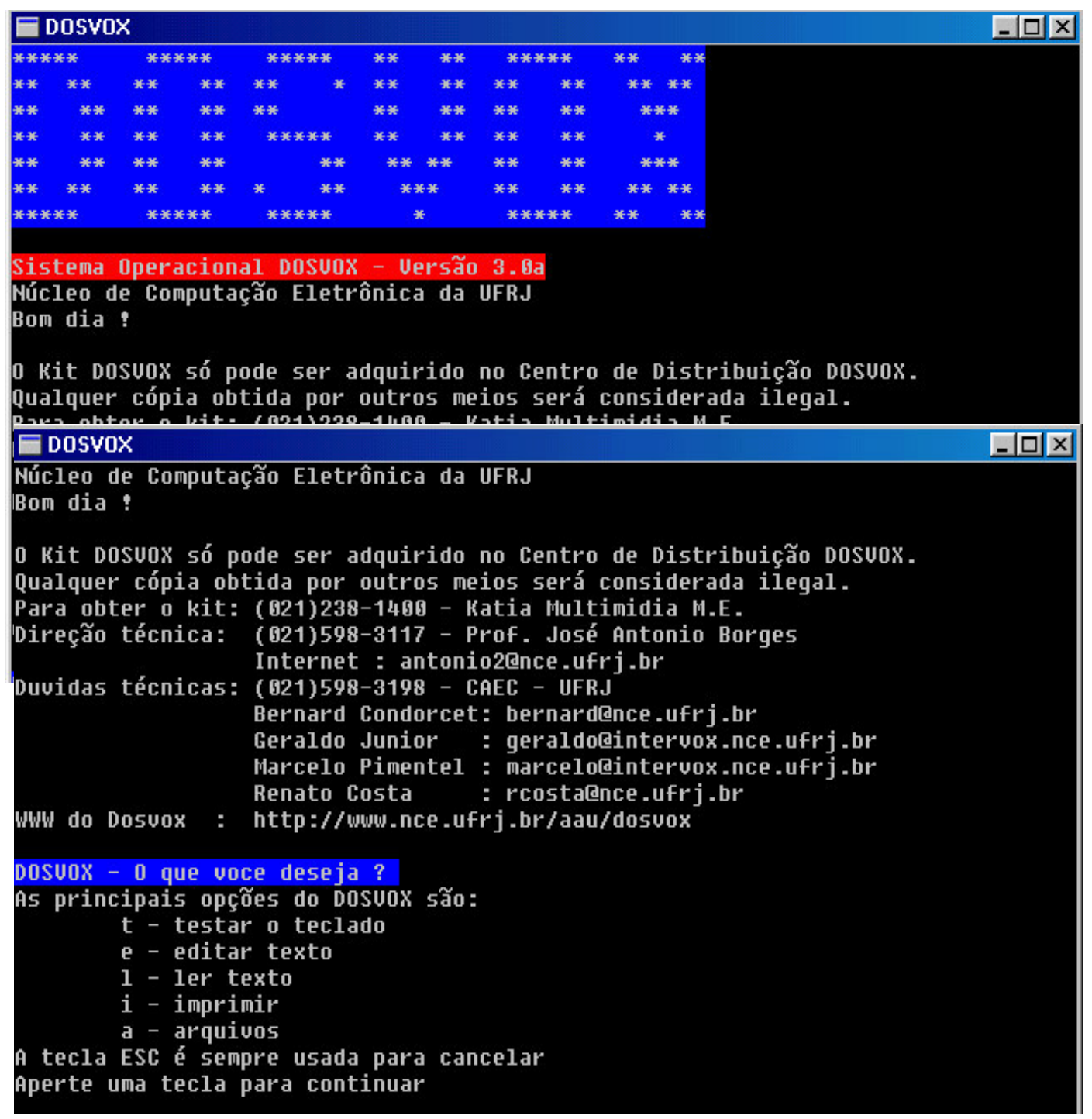

\section{Virtual Vision}

Desenvolvido pela MicroPower (empresa de Ribeirão Preto - SP). A primeira versão foi lançada em janeiro de 1998 e em setembro de 1999 a versão 2.0. Sua última versão é a 4.0. Pode ser adaptado em qualquer programa do Windows. É uma aplicação 
da tecnologia de síntese de voz, um "leitor de telas" capaz de informar aos usuários quais os controles (botão, lista, menu,...) estão ativos em determinado momento. Pode ser utilizado inclusive para navegar na Internet. Segundo informações de seu fabricante, o Virtual Vision é atualmente acessado por aproximadamente 4.500 pessoas.

Dentre suas principais características, destacam-se:

* Funciona em programas para Windows (nas versões 95, 98, XP, NT e 2000), seus aplicativos Office, programas para acesso à Internet (com o Internet Explorer), programas de e-mail, programas de OCR (reconhecimento óptico de caracteres), etc;

* Pronuncia as palavras digitadas letra por letra, palavra por palavra, linha por linha, parágrafo por parágrafo ou todo o texto. O próprio usuário pode determinar suas preferências. Ao teclar a barra de espaço, o software lê a palavra inteira digitada;

* Utilizando o Sistema Operacional Windows é possível ouvir músicas de um CD ou de um arquivo MP3, desde que o Virtual Vision seja emudecido, pois esse utiliza o áudio da placa de som;

* Permite o rastreamento do mouse ou, em outras palavras, digitaliza o que está em baixo do cursor do mouse em movimento (pode-se ligar e desligar esta opção);

* Pronuncia detalhes sobre os controles do Windows, tais como: tipo de controle, estado, etc (pode-se ligar e desligar esta opção);

* Seu sintetizador de voz é muito bom, além de ser, é claro, em português.

* Possui um módulo de treinamento "falado" e um panorama do ambiente Windows 95;

* Permite a fácil localização do cursor na tela através de teclas de atalho;

* Totalmente auto-instalável permitindo a operação do sistema/aplicativos via teclado ou mouse;

* Pronuncia detalhes sobre a fonte de texto (nome, tamanho, cor, estilo, etc.), bem como as mensagens emitidas pelos aplicativos;

* Não requer nenhum outro equipamento adicional (dispensa o sintetizador externo);

* Através de uma impressora Braille e um software como o Braille Creator o usuário pode imprimir qualquer página da internet, de documentos, de e-mail, etc;

* Através do Virtual Vision, é possível digitalizar um texto para posterior impressão em braille, desde que o scanner utilizado possua o programa OCR;

* Através de parcerias com o Banco Bradesco e Brasil Telecom, os deficientes visuais podem utilizar os serviços disponíveis, acessando os sites dessas empresas;

Permite a leitura de páginas da Internet citando, inclusive, os links para outras páginas, embora não seja tão eficiente em sites com frames e tabelas.

Acaba de ser lançada a última versão do Virtual Vision, a 4.0 que promete muitas melhorias em relação às versões anteriores, dentre as quais:

* Maior facilidade de navegação na Web;

* Integração total com o Office 2000/XP;

* Multi-idiomas: português e inglês, além de permitir a expansão para outros idiomas; 
* Leitura automática de textos em janelas de assistentes (Wizards);

* Permite a configuração de diferentes variações de voz para a identificação da formatação e capitalização de textos.

No que tange ao preço do Virtual Vision, a versão atual é comercializada, sendo gratuita para correntistas do Brasdesco. As versões para Windows XP, NT e 2000 são mais caras. Programas similares importados têm preços superiores.

\section{Jaws}

Programa desenvolvido pela empresa norte-americana Henter-Joyce, pertencente ao grupo Freedom Scientific. O Jaws para Windows é um leitor de telas que permite facilmente o acesso ao computador a pessoas cegas ou amblíopes. Com o Jaws, qualquer usuário deficiente visual pode trabalhar tão ou mais rapidamente do que uma pessoa que veja normalmente, utilizando teclas de atalho. Estima-se que atualmente a quantidade de usuários deste programa esteja em torno de 50.000, espalhados por vários países.

É um software de fácil utilização, eficiente e a velocidade pode ser ajustável conforme o nível de cada usuário.

O Jaws trabalha em ambiente Windows, nas versões 95, 98, ME, NT, XP e 2000. Após sua instalação, que também é digitalizada, possibilita o uso da grande maioria dos aplicativos existentes para o ambiente Windows, como Office, Internet Explorer, E-mail, Chat, Instant Messaging, entre outros sem qualquer dificuldade. Adaptar-se é uma característica muito importante do Jaws para Windows.

As suas características principais são:

* Facilidade na instalação e apoio por voz durante o processo;

* Roda aplicações MS-DOS;

* É atualizado por volta de duas vezes ao ano;

* Apesar de possuir sintetizador de software próprio, Eloquency, pode também usar outros sintetizadores de software ou externos;

* Possui síntese de voz em vários idiomas, incluindo o português do Brasil (a partir da versão 3.7), permitindo a alteração deste durante sua utilização;

* Faz indicação das janelas ativadas, do tipo de controle e suas características;

* Processa a leitura integral dos menus, com indicação da existência de submenus;

* Digitaliza as letras e palavras digitadas, estando adaptado ao teclado português;

* A leitura pode ser feita por letra, palavra, linha, parágrafo ou a totalidade do texto;

* Possibilita a leitura dos textos em qualquer área de texto editável;

* Fornece indicação da fonte, tipo, estilo e tamanho da letra que está sendo utilizada;

* Permite trabalhar com Correio Eletrônico e navegar na Internet, como se estivesse em um processador de texto;

* Permite o controle do mouse, para as operações que não o dispensem, bem como seu rastreamento, lendo o que está por baixo dele;

* Possui uma ajuda de teclado, que digitaliza as funções de cada tecla.

* Em qualquer ponto de uma aplicação pode-se obter ajuda (sobre as seqüências de teclas, sua aplicação e do próprio Jaws);

* Possibilita a etiquetagem de gráficos;

* Possui dicionários, geral ou específico, que permitem controlar a maneira como as palavras, ou expressões, são pronunciadas; 
* As definições de configuração podem ser ajustadas para a generalidade das aplicações, ou apenas para aplicações específicas.

Uma das grandes vantagens do Jaws, de acordo com alguns usuários, é o fato dele simular o mouse através do teclado (o botão esquerdo é acionado através da tecla "barra" ("/") e o botão direito, através do "asterisco" ("*"), ambos do teclado numérico), possibilitando o acesso a programas que anteriormente eram dificultados ou mesmo impossíveis com outros leitores de tela. Assim, o usuário pode configurar o sistema de acordo com o tipo de programa que está utilizando, por meio de três tipos de cursores:

* Cursor Jaws: movimenta o cursor (mouse) através das setas de direção do teclado. Para ativá-lo utiliza-se a tecla "-" (menos) do teclado numérico;

* Cursor PC: apresenta função semelhante a do Virtual Vision. É o modo normal de trabalho, também chamado de cursor do micro. Lê o conteúdo nele posicionado. Para ativá-lo utiliza-se a tecla "+" (mais) do teclado numérico;

* Cursor Invisível: apresenta uma capacidade de leitura superior aos anteriores, lendo inclusive o que se encontra por traz das janelas (o conteúdo que não aparece na tela). Consegue ler praticamente todos os botões, seus detalhes e os frames das páginas da Internet. Para ativá-lo deve ser pressionada duas vezes a tecla "-" (menos) do teclado numérico.

Outra importante função do Jaws é o fato deste permitir que o usuário configure a intensidade da leitura. Esta pode ser do tipo "Ampla", "Restrita" ou "Ausente", ambas ativadas através das teclas "INS" + "s". Assim o sistema oferece por exemplo a possibilidade da leitura ou não de frames ou outros recursos adicionais.

A versão atual é a 4.5 embora não esteja ainda totalmente traduzida para o português. Esta apresenta algumas vantagens em relação às anteriores, quais sejam:

* suporte a linguagem Flash, utilizada no desenvolvimento de algumas páginas da Internet;

* melhorias na utilização do Internet Explorer, de scripts Java e dos programas Word, Excel, Winamp e Acrobat Reader;

* as teclas de navegação possuem um desempenho mais rápido em páginas da Web, formulários e tabelas;

* compatibilidade com programas de leitura de DVD;

Quanto ao preço, a versão demo de 40 minutos pode ser capturada do site do fabricante gratuitamente; a versão demo de 60 dias está disponível por baixo preço; a versão para Windows 95/98 e a versão completa para Windows NT ou 2000 são mais onerosas. As licenças para empresa estão disponíveis em múltiplos de cinco, com descontos variando de 30 a $40 \%$, dependendo do número de usuários.

\section{Funcionamento do JAWS}

Como o Jaws (e também o Virtual Vision) é um leitor de telas, seu funcionamento é simples, desde que o usuário tenha conhecimento das teclas de atalho. Após instalação podemos acrescentar seu ícone na área de trabalho ou acioná-lo através de sua tecla de atalho: "CTRL+ALT+J".

Assim, a partir do momento que o Jaws é acionado ele passa a "ler" as ações desempenhadas pelo usuário. Uma janela do programa fica minimizada na Área de Trabalho do Windows. Ao ativá-la (figura 3) esta permite alterar configurações da leitura das telas. 


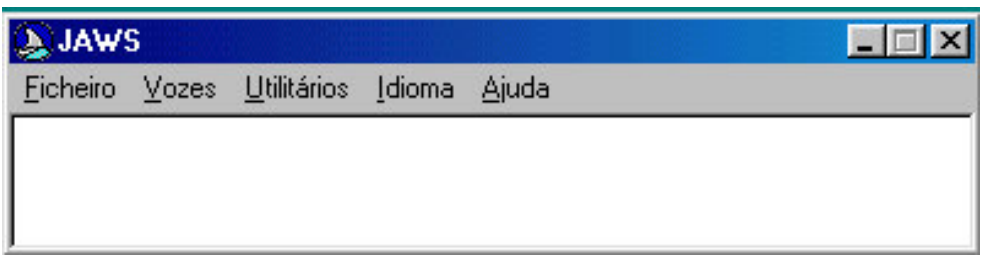

Figura 3 - Janela de Configuração do Jaws.

\section{Considerações finais}

Podemos salientar que o computador, aliado a uma prática pedagógica comprometida com a formação de cidadãos, é uma poderosa ferramenta para o processo ensino-aprendizagem, contribuindo fortemente para propiciar o desenvolvimento cognitivo e sócio-afetivo das PNEEs. Contudo este recurso é apenas um mediador do processo que deve estar associado a outro mediador como por exemplo ao professor, aos sistemas simbólicos, entre outros que favorecerão esse desenvolvimento.

No contexto de prática pedagógica, auxiliada pelo computador, o papel do professor deixa de ser o de repassador de conhecimento, o "sabe tudo" para ser o "criador de ambientes de aprendizado e desenvolvimento", o facilitador do processo pelo qual o aluno tem possibilidade de contribuir. A entrega do conhecimento "digerido" é então substituída por desafios, que levam em conta a realidade do aluno, seus desejos, necessidades e vontades. Desta forma, o sujeito do aprendizado passa a ter condições de exercer sua criatividade, de "liberar sua mente"

Podemos dizer que as vantagens que a Informática nos propicia são inúmeras, desde que bem utilizadas. Todo o dia novos softwares e equipamentos são desenvolvidos nas mais diversas áreas, incluindo a educação. E há um segmento desta que tem sido muito beneficiado com isso - A Educação Especial, que está se valendo deste recurso tecnológico de duas formas: como prótese no sentido de adequar ou adaptar equipamentos para que esta população também faça uso deles, e como meio de aprendizagem.

No caso dos deficientes visuais os três sistemas mais utilizados no Brasil hoje são o DOSVOX, o VIRTUAL VISION e o JAWS. Os dois primeiros são projetos nacionais, sendo o DOSVOX bastante utilizado por ser relativamente fácil de se aprender, gratuito (na sua versão reduzida) e de processamento rápido. Quanto ao JAWS, é um sistema americano, há pouco tempo traduzido para o português, e talvez seja prematuro ainda afirmar que substitua o VIRTUAL VISION, embora o relato de alguns deficientes visuais que já o utilizam é de que ele pareça ser o melhor leitor de telas para a maioria das aplicações no computador.

Pensamos que tais softwares, mesmo com algumas limitações, facilitam muito o acesso dos deficientes visuais ao computador, garantindo-lhes um ótimo nível de independência e autonomia, motivando-os e oportunizando sua inclusão aos ambientes digitais no mundo da comunidade dos cibernautas. 


\section{Referências bibliográficas}

ACIC - Associação Catarinense para Integração do Cego. Acessibilidade - nós podemos usar o computador, sim. Disponível em <http://www.jornalismo.ufsc. br/acic/acesso> Acesso em Set/2002.

BORGES, José Antônio. Manual do Dosvox. Núcleo de Computação Eletrônica da UFRJ - Universidade Federal do Rio de Janeiro. <http://www.nce.ufrj.br>.

BORGES, José Antônio. Dosvox - um novo acesso dos cegos à cultura e ao trabalho. Revista Benjamin Constant, $\mathrm{n}^{\circ} 3$ - maio de 1996. (IBCENTRO/MEC).

CAMPBELL, Larry. Trabalho e cultura: meios de fortalecimento da cidadania e do desenvolvimento humano. Revista Contato - Conversas sobre Deficiência Visual Edição Especial. Ano 5, número 7 - Dezembro de 2001.

CONFORTO, Débora e SANTAROSA, Lucila M. C. Acessibilidade à Web: Internet para Todos. Revista de Informática na Educação: Teoria, Prática PGIE/UFRGS.2002 (no prelo).

FONTES, Marcos F. Manual de Iniciação à Informática para Deficientes Visuais. Dow Química, 1999.

GIL, Marta (org). Deficiência Visual. Ministério da Educação. Secretaria de Educação à Distância, $\mathrm{n}^{\circ}$ 1/2000. Disponível em <http://www.mec.gov.br/seed/tvescola/ pdf/deficienciavisual.pdf>. Acesso em Set/2002.

HOGETOP, L e SANTAROSA, L.M.C, Tecnologias Adaptiva/Assistiva Informáticas na Educação Especial: viabilizando a acessibilidade ao potencial individual. Revista de Informática na Educação: Teoria, Prática - PGIE/UFRGS.2002 (no prelo)

IGOIA - Jaws 3.5 for Windows. Disponível em <http://www15.brinkster.com/igoia /acessibilidade/caracteristicasdosleitoresdetela.asp> Acesso em Out/2002.

LDB (Lei de Diretrizes e Bases) 96 - Lei n 9.394, de 20 de dezembro de 1996. Brasília, 2002. Disponível em <http://www.mec.gov.br/ibc/hist.htm> Acesso em Set/2002.

LERPARAVER - O Portal da Visão Diferente. Antônio Silva e Daniel Serra. Disponível em <http://www.lerparaver.com> Acesso em Jan/2003.

MICROPOWER - Tecnologia em Educação e Negócios. Disponível em <http://www. micropower.com.br> Acesso em Jan/2003.

NIEE - UFRGS - Núcleo de Informática na Educação Especial - Universidade Federal do Rio Grande do Sul - Disponível em <http://www.niee.ufrgs.br> Acesso em Nov/2002.

SANTAROSA, Lucila. M. C. Informática como "prótese" na educação especial. 
Revista de Informática Educativa, Bogotá/Colômbia 2(4): 105-130, ago. 1991.

SANTAROSA, Lucila M. C. Comunicar para aprender, aprender para comunicar: Ambientes de aprendizagem telemáticos como alternativa. Brasília, Revista Integração, (8) 20:46-50, 1998.

SANTAROSA, Lucila M. C. Telemática y la inclusión virtual y social de personas con necesidades especiales: un espacio posible en la Internet - RIBIE 2000 - Chile. Disponível <http://www.c5.cl/ieinvestiga/actas/ribie2000> Acesso em Nov/2002.

SANTAROSA, Lucila M. C. Entrevista. Revista Integração, Ministério da Educação Secretaria de Educação Especial. Brasília, Ano 13 - n 23/2001.

SANTAROSA, L. M. C. Cooperação Na Web Entre PNEE: construindo conhecimento no Núcleo de Informática na Educação Especial da UFRGS. Anais do Congresso Ibero-americano de Informática na Educação especial- III CIIEE- SEESP/MEC. Fortaleza 20 a 23 de agosto 2002 publicado em meio digital - CD - p.64-79.

SANTOS, Marilene R. Aspectos políticos e científicos na educação, na saúde e no trabalho da pessoa com deficiência visual. Revista Contato - Conversas sobre Deficiência Visual - Edição Especial. Ano 5, número 7 - Dezembro de 2001.

SIDNEY, Jucimar Luiza Juçá. Inclusão Escolar. Disponível em <http://www.sac.org.br /APR_INC.htm> Acesso em Nov/2002.

VALENTE, José Armando. Liberando a Mente: Computadores na Educação Especial. Campinas: Editora da UNICAMP, 1991. 